\title{
MARKETING DE RELACIONAMENTO NAS MICROEMPRESAS: EM BUSCA DA FIDELIZAÇÃO DE CLIENTES
}

\author{
Jéssica Cecilia Capasso, Jéssica Ferreira, Thais Duarte dos Santos, Thais Rubia Ferreira Lepre \\ Universidade do Oeste Paulista - UNOESTE, TCS Gestão Comercial, Presidente Prudente, SP. E-mail: \\ thaisrubia@unoeste.br
}

\begin{abstract}
RESUMO
Vivenciamos uma época de diversidades, em todos os sentidos, inclusive com relação as opções disponíveis para os consumidores, que a cada dia que passa sentem-se mais empoderados e buscam não apenas comprar, e sim criar relações de consumo. Motivo pelo qual o marketing de relacionamento esta recebendo tanto destaque das organizações atualmente. Esta forma de aplicação do marketing tem como finalidade o relacionamento que gera a fidelização de clientes, e pode ser utilizado por empresas de qualquer porte, inclusive microempresas, que possuem recursos bastante limitados para investimento. O desafio esta em saber quais ferramentas utilizar, justificando a existência deste estudo que visa discutir ferramentas de marketing de relacionamento para microempresas, beneficiando com informação, a todos os microempresários brasileiros, considerando que a problemática que o objetivo deste artigo é identificar ferramentas de marketing de relacionamento que podem ser utilizadas pelas microempresas para fidelização de clientes. E para tanto optou-se por uma abordagem qualitativa, tendo a pesquisa bibliográfica como instrumento de coleta e analise de conteúdo, como técnica de análise. Foi possível concluir que dentre as diversas ferramentas disponibilizadas pelo marketing de relacionamento, o CRM, o endomarketing e o banco de dados são relevantes na busca pela fidelização de clientes.
\end{abstract}

Palavras-chave: Marketing de Relacionamento. Microempresa. Fidelização. Cliente. Ferramentas.

\section{RELATIONSHIP MARKETING IN SMALL BUSINESS: THE SEARCH FOR CLIENT FIDELIZATION}

\begin{abstract}
We are experiencing a time of diversity, in every sense, including the options available to consumers, who each day feel more empowered and seek not only to buy, but to create consumer relations. Reason why relationship marketing is getting so much prominence from organizations today. This form of marketing application has as its purpose the relationship that generates customer loyalty, and can be used by companies of any size, including micro-enterprises, which have very limited resources for investment. The challenge is to know what tools to use, justifying the existence of this study that aims to discuss relationship marketing tools for small business, benefiting with information, to all Brazilian microentrepreneurs, considering that the problem that the objective of this article is to identify marketing tools of Relationship that can be used by small business to customer loyalty. For this, a qualitative approach was chosen, with bibliographical research as an instrument for collecting and analyzing content as a technique for analysis. It was possible to conclude that among the several tools offered by relationship marketing, CRM, endomarketing and database are relevant in the search for customer loyalty.
\end{abstract}

Keywords: Marketing of relationship. Micro enterprise. Loyalty. Client. Tools.

\section{INTRODUÇÃO}

O fenômeno da globalização contribuiu para um mercado cada vez mais dinâmico, mas nem sempre foi dessa maneira. Antes as empresas se preocupavam em disponibilizar o "básico" 
no mercado, produto/serviço do quais seriam consumidos, ou seja, vendiam de maneira fácil, pois o consumidor não se preocupava em pesquisar qual o produto/serviço mais barato ou o melhor.

Atualmente já não é dessa forma, com a globalização, avanços tecnológicos e clientes mais exigentes, as empresas têm que estar em constante alerta para não perder participação de mercado. E identificar o que os clientes necessitam e desejam, para oferecer produtos e serviços adequados, é uma forma de aumentar a possibilidade de venda. E é neste ponto, que o marketing pode auxiliar os negócios: a atrair e fidelizar clientes.

E não somente as grandes empresas (como muitos acreditam), podem utilizar o marketing, todas podem, inclusive as microempresas, que dominam o mercado empresarial brasileiro atualmente. E uma das funções do marketing mais buscadas por gestores deste porte de negócio é fidelização de clientes, pois contam com poucos recursos para investimento e fidelizar o cliente já atraído custa menos do que o esforço para atrair novos interessados. Justificando a existência deste artigo que visa discutir ferramentas de marketing de relacionamento para microempresas, beneficiando com informação, a todos os microempresários brasileiros, considerando que a problemática que este artigo pretende responder é: quais ferramentas de marketing de relacionamento podem ser utilizadas pelas microempresas para fidelização de clientes?

Assim, o objetivo deste estudo recai em identificar ferramentas de marketing de relacionamento que podem ser utilizadas pelas microempresas para fidelização de clientes.

\section{METODOLOGIA}

Diante da necessidade de coerência entre o objetivo estabelecido e os métodos utilizados para seu alcance, este artigo foi realizado através de abordagem qualitativa, que de acordo com Fachin $(2005$, p. 81) "[...] é caracterizada pelos seus atributos e relaciona aspectos não somente mensuráveis, mas também definidos descritivamente", justificando sua escolha para este artigo, que visa a compreensão do assunto estudado e não a mensuração de variáveis.

Neste sentido, a técnica de coleta de dados utilizada foi a pesquisa bibliográfica, em que se utilizou informações já publicadas, disponibilizadas através de livros, artigos e sites relevantes na área, considerando que (2002, p.122) "a pesquisa bibliografia é a que se desenvolve tentando explicar um problema, utilizando o conhecimento disponível a partir das teorias publicadas em livros ou obras congêneres" (KÖCHE, 2002, p.122).

E como forma de explorar ao máximo os dados coletados através do uso deste método, realizou-se uma analise de conteúdo. Tendo em vista que "[...] através da análise de conteúdo, podemos caminhar na descoberta do que está por trás dos conteúdos manifestos, indo além das aparências do que está sendo comunicado". (GOMES, 2007, p. 84). Ou seja, esta analise permitiu compreender profundamente os dados, indo além do que parecia ser, para o que realmente é.

\section{RESULTADOS}

Nesta seção serão apresentados todos os resultados encontrados com esta pesquisa, realizada a partir de materiais já publicados.

\section{Microempresa}

De acordo com o Instituto Brasileiro de Geografia e Estatística - IBGE (2006), "no Brasil existem 4,6 milhões de empresas, sendo que, desse total, 99\% são micro e pequenas empresas". Ou seja, estas modalidades de negócios são essenciais para o desenvolvimento econômico do país, pois são responsáveis por grande parte dos empregos e da renda gerados. E este número só vem aumentando, 460 mil novos negócios deste porte surgem anualmente no Brasil (WANKE; MAGALHÃES, 2012). Deste modo, é possível observar que anualmente há um crescimento de quase meio milhão de microempresas no mercado, fazendo com que haja um grande número de formação de novos empregos. 
A forma mais usual de caracterizar uma microempresa é por meio do número de colaboradores e do seu faturamento anual. A tabela a seguir trás a classificação de acordo com o número de colaboradores:

TABELA 1 - Classificação de porte de acordo com o número de colaboradores

\begin{tabular}{|c|c|c|}
\hline \multirow{2}{*}{ Porte } & \multicolumn{2}{|c|}{ Setores } \\
\hline & Indústria & Comércio e Serviços $^{n}$ \\
\hline Microempresa & até 19 pessoas ocupadas & até 9 pessoas ocupadas \\
\hline Pequena empresa & de 20 a 99 pesscas ccupadas & de 10 a 49 pessoas ccupadas \\
\hline Média empresa & de 100 a 499 pessoas ocupadas & de 50 a 99 pessoas ocupadas \\
\hline Grande empresa & 500 pessoas ocupadas ou mais & 100 pessoas ccupadas ou mais \\
\hline
\end{tabular}

Fonte: Sebrae e Dieese (2013)

Desta tabela é possível observar que para ser considerada microempresa o máximo de colaboradores que uma indústria pode possuir é até 19, e se for um comércio, apenas 09 pessoas.

O faturamento é outra forma de caracterizar e diferenciar uma microempresa dos demais portes. Segundo o Art. 3ㅇda Lei Complementar 123 de 14 de dezembro de 2006:

Art. 3o Para os efeitos desta lei complementar consideram-se microempresas ou empresas de pequeno porte a sociedade empresária, a sociedade simples, a empresa individual de responsabilidade limitada e o empresário a que se refere o art. 966 da Lei no 10.406, de 10 de janeiro de 2002 (Código Civil), devidamente registrado no registro de empresas mercantis ou no registro civil de pessoas jurídicas, conforme o caso, desde que: I - no caso da microempresa, aufira, em cada ano-calendário, receita bruta igual ou inferior a $\mathrm{R} \$ 360.000,00$ (trezentos e sessenta mil); e II - No caso da empresa de pequeno porte, aufira, em cada ano-calendário, receita bruta superior a $\mathrm{R} \$ 360.000,00$ (trezentos e sessenta mil reais) e igual ou inferior a $\mathrm{R} \$ 3.600 .000,00$ (três milhões e seiscentos mil reais).

Ou seja, para ser considerada microempresa o faturamento máximo do negócio não pode ultrapassar $\mathrm{R} \$ 360.000,00$ por ano.

\section{Marketing de Relacionamento e Ferramentas Para Fidelização de Clientes}

Muito se fala no marketing desde a época da revolução industrial, quando a tecnologia possibilitou a produção em massa, tornando a oferta de produtos superior a demanda, e como forma de destacar-se da concorrência as empresas começaram a adotá-lo. Tendo em vista que marketing "envolve a identificação e a satisfação das necessidades humanas e sociais. [...] podemos dizer que ele 'supre necessidades humanas'" (KOTLER; KELLER, 2006, p.4). Auxiliando as empresas na oferta dos produtos que seus consumidores necessitam e desejam.

Mas desta época até os dias atuais, o mercado sofreu grandes mudanças, sendo o aumento das exigências do consumidor, uma das principais, surgindo assim, uma nova aplicação do marketing: o marketing de relacionamento.

Segundo Kotler (1998, p. 30):

Marketing de relacionamento é a prática da construção de relações satisfatórias a longo prazo com partes-chaves - consumidores, fornecedores e distribuidores - para reter sua preferência e negócios a longo prazo. As empresas inteligentes tentam desenvolver confiança e relacionamentos "ganha-ganha" a longo prazo com consumidores, distribuidores, revendedores e fornecedores. Realizam isso prometendo e entregando alta qualidade, bons serviços e preços justos as outras partes 
no decorrer do tempo. Marketing de relacionamento resulta em fortes vínculos econômicos, técnicos e sociais entre as partes. Também reduz os custos de transação e o tempo. Na maioria dos casos bem-sucedidos, as transações passam a ser rotineiras, em vez de serem tratadas caso a caso.

Com o Marketing de Relacionamento as organizações buscam a criação de comprometimento e confiança, construindo laços a longo prazo e sua característica é focada no cliente como único, onde tudo é criado para o cliente.

Segundo Gonçalves, Jamil e Tavares (2002, p. 96) o marketing de relacionamento objetiva "manter clientes satisfeitos após a compra e, se necessário, recuperá-los: fazer tudo para que o cliente recompre o produto da mesma empresa; mensurar a satisfação de clientes; realizar comunicação pós-venda; receber feedback; criar eventos e canais; ter serviço de qualidade e relações públicas".

O marketing de Relacionamento está fortemente relacionado com a fidelização, pois essa é de grande importância no ambiente coorporativo. Stone \& Woodcock (1998), afirmam que a fidelidade é um compromisso físico emocional assumido por um cliente em troca de suas necessidades e desejos serem atendidas. Quando existe um bom relacionamento entre a empresa e o cliente, a fidelização existe. E existem diversas formas das empresas conquistarem a fidelização de seus clientes, sendo as ferramentas disponibilizadas pelo marketing de relacionamento, uma das principais. E diante da diversidade de ferramentas existentes, neste artigo, optou-se por expor as mais populares e que não apresentam custo elevado (considerando as condições financeiras das microempresas), que são: o benchmarking, banco de dados e o CRM.

Iniciando pelo benchmarking, que é uma ferramenta importante na análise dos seus concorrentes, analisando as melhores práticas adotadas com relação a fidelização de clientes para posterior melhoria e utilização, ou seja, consiste em melhorar estratégias já usada pela concorrência, ou seja, reformula-las a seu favor, modificando de acordo com seu campo de negócio, fazendo adaptações e corrigindo pontos poucos favoráveis. Gariba Junior (2005, p.43) ressalta que benchmarking é:

[...] um procedimento de pesquisa, contínuo e sistemático, pelo qual se realizam comparações entre organizações, objetos ou atividades, criandose um padrão de referência. A técnica de benchmarking visa, portanto, à procura de pontos de referência que comparem o desempenho com a concorrência, com o objetivo de melhorar o rendimento naquele aspecto que se quer medir.

Sendo assim, pode se dizer que benchmarking é uma pratica melhorada, direcionada para a empresa que aderi e aperfeiçoada aos costumes e cultura do negócio, levando consigo mais conhecimento e um ato continuo onde é melhorado a cada nova etapa.

Outra ferramenta importante para fidelização é o Banco de dados. Ronconi (2002) define, banco de dados como sendo um conjunto de informações referentes a determinado assunto, tendo como finalidade armazenar as informações, identificar clientes potenciais, decidir quais clientes receberam ofertas, aprofundar a fidelidade do cliente e reativar as compras.

Um banco de dados contém todas as informações possíveis dos clientes, e utiliza informações interna e externa para filtrar o marcado alvo, assim desenvolve o planejamento de vendas e ajuda a criar um atendimento diferenciado. Taticamente ele é um diferencial para empresas que conseguem administrar bem as informações recebidas e assim usa-las a seu favor para estreitar laços cliente/empresas.

E para finalizar, o CRM (Customer relationship management), que em português significa 'gestão do relacionamento com o consumidor', que é uma das ferramentas de marketing mais 
utilizadas para fidelização de clientes, pois consiste em "softwares e ferramentas analíticas sofisticados, de empresas [...] que integram as informações dos clientes provenientes de todas as fontes, analisam-nas em profundidade e utilizam os resultados obtidos para desenvolver um sólido relacionamento com o cliente" (KOTLER; ARMSTRONG, 2015, p.127). Essas informações contribuem para que a empresa conheça bem seus clientes, para que possa oferecer os produtos/serviços adequados as suas necessidades e desejos, conquistando assim, sua fidelização.

Para Lovelock e Wirtz (2006, p.317):

[...] sistemas de CRM bem implementados podem the oferecer uma interface unificada, o que significa que, em cada transação, os detalhes relevantes de uma conta, o conhecimento das preferências do cliente e de suas transações anteriores, ou histórico de um problema de serviço estão ao alcance dos dados da pessoa que está atendendo isso pode resultar em grande melhoria no serviço.

Enfim, essa ferramenta acaba facilitando a estratégia de atrair novos clientes, manter satisfeitos os atuais e criar novas oportunidades de mercado.

Para as Microempresas que adota essa ferramenta, elas passam a pensar melhor na propaganda que vai fazer, nos preços que pode reajustar nos seus produtos/serviços, e o que o seu cliente realmente necessita. Com isso alcança não só maior visibilidade de seus produtos/serviços, como também terá uma redução de custos significativas já que irá trabalhar em cima de dados concretos e mais certeiros.

\section{CONCLUSÃO}

O presente trabalho propôs demonstrar por meio de pesquisa bibliográfica as ferramentas de marketing de relacionamento recomendadas para as microempresas, afim de que as organizações possam utilizá-las como auxilio na busca pelo reconhecimento e sucesso da organização, podendo assim fidelizar seu público alvo.

O mercado está em constante evolução, proporcionando o aumento de concorrência no ambiente que está inserido, com os consumidores que estão cada dia mais exigentes e seletivos. Para conquistá-los é exigido das empresas novos esforços, entre eles, destaca-se a necessidade de estudar e implantar as ferramentas de marketing de relacionamento, para se obter uma saudável relação entre seus clientes internos e externos.

Diante dos estudos foi possível analisar que muitos pequenos empresários acabam não conhecendo as funcionalidades que o marketing de relacionamento dispõe para as microempresas desenvolverem seus negócios. Observa-se que entre as diversas ferramentas disponíveis do marketing de relacionamento, acredita-se que o benchmarking, banco de dados e o CRM, auxiliam na busca e reconhecimento e sucesso da organização, para fidelizar seu público alvo.

Conclui-se portanto, que quando as microempresas possuem o conhecimento e controle das corretas ferramentas de marketing de relacionamento a serem implantadas dentro da organização, possuem grandes oportunidades de crescimento, mantendo um forte relacionamento com seus clientes e conquistando novos.

\section{REFERÊNCIAS BIBLIOGRÁFICAS}

BEATRIZ, C. O marketing e o comportamento do consumidor. Disponível em: <http://www.convibra.com.br/upload/paper/adm/adm 3488.pdf> Acesso em: 01 ago. 2017.

Cartilha do Consumidor. Disponível em: <http://www.procon.al.gov.br/legislacao/cartilhadoconsumidor.pdf $>$ Acesso em: 25 jun. 2017. 
CEZARINO, Luciana; CAMPOMAR, M. Micro e pequenas empresas: Características estruturais e gerenciais.

Disponível

em:

$<$ http://www.unifafibe.com.br/revistasonline/arquivos/hispecielemaonline/sumario/10/19042010 081633.pdf> Acesso em: 25 jul. 2017.

GOMES, R. Análise e interpretação de dados de pesquisa qualitativa. In: MINAYO, M. C. de S (Org.). Pesquisa social: teoria, método e criatividade. 26. ed. Petrópolis: Vozes, 2007.

GONÇALVES, C. A.; JAMIL, G. L.; TAVARES, W. R. Marketing de relacionamento: Database Marketing. Rio de Janeiro: Axcel Books, 2002.

KÖCHE, J. C. Fundamentos de Metodologia Cientifica: Teoria da ciência e iniciação á pesquisa. 21. ed. Petrópolis: Vozes, 2002.

KOTLER, P.; ARMSTRONG, G. Introdução ao Marketing. 4. ed. Rio de Janeiro: Editora LTC S/A, 2000.

KOTLER, P.; ARMSTRONG, G. Princípios de Marketing. 15 ed. São Paulo : Pearson Education do Brasil, 2015.

KOTLER, P.; KELLER, K. L. Administração de marketing. 12. ed. São Paulo: Pearson Prentice Hall, 2006.

SANTOS, A.; KREIN, J.; CALIXTRE, A. Micro e Pequenas Empresas Mercado de Trabalho e Implicação para o Desenvolvimento. Rio de Janeiro: IPEA, 2012.

Sebrae, Serviço brasileiro de apoio à micro e pequenas empresas. Entenda as diferenças entre microempresa, pequena empresa e MEI Disponível em: <https://www.sebrae.com.br/sites/PortalSebrae/artigos/entenda-as-diferencas-entremicroempresa-pequena-empresa-e-mei,03f5438af1c92410VgnVCM100000b272010aRCRD> Acesso em: 05 mai. 2017.

Secretaria da Micro e Pequena Empresa Presidência da República. Tratamento Diferenciado às Micro e Pequenas Empresas: Legislação para Estados e Municípios. Disponível em: <http://www.smpe.gov.br/assuntos/cartilha tratamentodiferenciado mpe.pdf> Acesso em: 05 mai. 2017.

STONE, M.; WOODCOCK, N. Clientes: marketing de relacionamento. Rio de Janeiro: Littera Mundi, 1998.

WANKE, P. F.; MAGALHÃES, A. Logística para micro e pequenas empresas. 1.ed. São Paulo: Atlas, 2012. 